\title{
Mother And Father's Behavioral Practices Towards Children With And Without Intellectual Disability Disorder (IDD)
}

\author{
Shaista Naz \\ \& \\ Nasir Sulman \\ Department of Special Education \\ University of Karachi
}

\begin{abstract}
The study has been emphasized that adequate behavioral parents made by parents with children with intellectual disability disorder (IDD) is essential for healthy development of these children. The parental behavioral practices of the 150 families of normal children have been used as comparison with the 150 families having a child with IDD. Participants of the study have been selected from three special schools of Karachi. The structured interview procedure was adopted and at the end of printed schedule a blank page was left to write down about any information which was not covered in the questionnaire. The findings demonstrated that there are differences between fathers and mothers in their behavioral practices towards children with IDD. It seems that future research in Pakistan must be directed toward a better understanding of the differential behavioral practices demonstrated by both mother and father.
\end{abstract}

Keywords: Intellectual Disability Disorder (IDD), Behavioral Practices, Parents, Parental Rejection, Modifying Attitude.

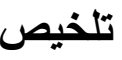

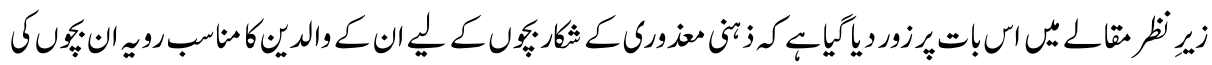

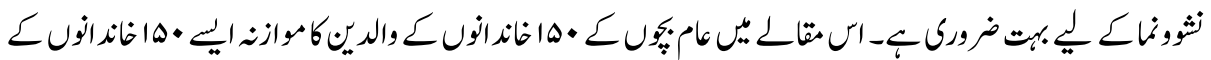



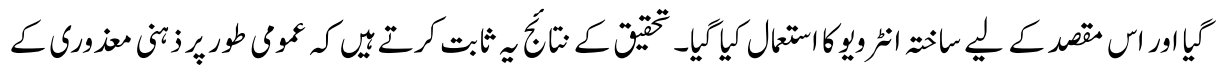

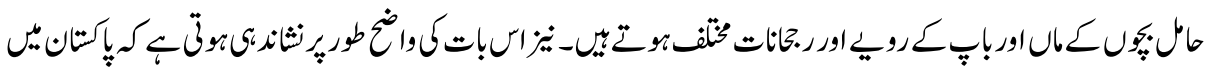

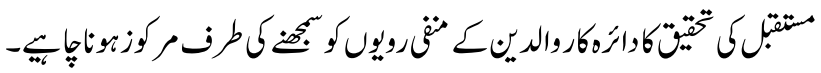






\section{Introduction}

Parents anticipate the birth of a healthy child, and characteristically, they look forward to their child's future achievement in school, success in a profession, marriage, and the birth of grandchildren. Thus, the birth of a handicapped child can have a devastating effect on parents (Thomas, 2015). Even when parents later discover that their school-aged child is handicapped (e.g., diagnosed as having a learning disability or as being intellectual disability disorder), Fleron (2017) reported that parents may need to undergo stages of recognition wherein they achieve acceptance of the child and make an appropriate reassessment of their expectations.

\section{Parental Rejection}

In a classic work, Gallagher (1956) defined rejection as "the persistent and unrelieved holding of unrealistic negative values of the child to the extent that the whole behavior of the parent towards the child is colored unrealistically by this negative tone." According to Gallagher, there were four ways in which parents could express rejection: (1) by having unreasonably low expectations, (2) by setting unreasonably high expectations, (3) by escaping the child by desertion or removal of the child from the home environment, or (4) by using the mechanism of reaction formation. In reactionformation the parents defends against the expression of an unacceptable impulse by expressing the opposite feeling. The parent cannot admit to other feelings and believes his or her expression of positivity when indeed he or she feels very negative about his or her child.

Gallagher also distinguished between primary and secondary forms of rejection. In primary rejection the negative attitudes of the parents are the result of, "the basic unchangeable nature of the child." For example, a mother rejects her mentally retarded daughter who will never achieve the professional status she desired for herself. Secondary rejection is the result of the behaviors exhibited by the child; for example, the unusual body movements of a child with cerebral palsy. Unfortunately, as Gallagher noted, it is difficult to distinguish between primary and secondary rejection. Consequently, professionals should assume that parents are evidencing secondary rejection and attempt to modify the behaviors of the child; if parental negativity persists even though many behavior problems have been brought under some form of control, primary rejection may be indicated.

According to Bryant (1971), the three parental attitudes most frequently observed by professionals in a clinical setting are: (1) acceptance; (2) rejection; and (3) compensation. Bryant describes the compensating parent as one who is trying to replace negative or rejecting attitudes with positivity or acceptance. As illustrated in Table 1, the 
compensation may be the result of various combinations of acceptance and rejection, with end products that may be harmful to the handicapped child.

Table: 1

Combinatorial responses of compensating parents

\begin{tabular}{|l|c|c|c|c|}
\hline \multicolumn{1}{|c|}{ Acceptance } & & Rejection & & Compensation \\
\hline Love & + & Indifference & $=$ & Possessiveness \\
\hline Empathy & + & Selfishness & $=$ & Sympathy \\
\hline Forgiveness & + & Fault Finding & $=$ & Over permissiveness \\
\hline Gentleness & + & Cruelty & $=$ & Smothering \\
\hline Caution & + & Carelessness & $=$ & Suspicion \\
\hline Activity & + & Apathy & $=$ & Overactivity \\
\hline
\end{tabular}

\section{Parentalplegia}

Murray and Cornell (1981) proposed a term "Parentalplegia" to describe a cyclical process wherein parents fail to adjust to having a handicapped child, respond inappropriately and possibly exacerbate their child's physiological impairment. Ferguson (2002) stated that over-protection, rejection, and "unrealistic prodding" are the most common types of parentalplegia. According to Horne (2012), parental rejection of a handicapped child may take the form of: (1) "cold rejection" and unfeeling response; (2) "rationalized rejection" wherein parents consider placing the child in an institutional situation because the placement can provide the specialized care the child needs; (3) "dutiful caring" without any warmth; or (4) "lavish care" wherein parents overcompensate for their rejecting attitude.

The purpose of this study is to analyze both mother and father's behavior in the context of Pakistan towards their child with intellectual disability disorder (IDD). The parental practices may have a significant effect on the social, emotional, and psychological development of the child with handicapped, in general; and child with IDD, in particular.

\section{Review of the Literature}

Some of the important recent research works which are related with the present research are reviewed as under:

Psaila (2016) describes the three stages of parental reaction to the discovery that their child is intellectually disabled. At the first stage the parents are shocked and they try to disbelief the fact, in the second stage they partially accept and partially deny the fact and the third stage achieved only by some, is that of reintegration followed by mature adaptation. 
Dabrowska \& Pisula (2010) discusses about the reactions of a family to intellectual disability. After discovery of the fact that their child is intellectually disabled the parents seem to go through the four stages of reactions. At first stage they get a shock, in the second stage they disbelieve the fact, in the third stage they are afraid and become frustrated and finally they accept the fact. In this journey of trauma, the authors advised that normal children should not be neglected and they should not be over emotional with the intellectually disability disordered child.

Hasnat\& Graves (2000) finds that the normal siblings and parents are not opposed the participation of intellectual disabled child in recreational activities, because during observation of different activities it was observed that the behavioral characteristics of the children with IDD fell well within the range of those exhibited by normal children.

Hastings (2003) studied the attitude of parents towards children with and without intellectual disability in four countries namely Yugoslavia, Germany, USA and Israel which differ culturally, economically and politically. The author conclude that the attitude of the mothers toward their children with IDD were more positive than the attitude of the mothers of the children without IDD. Dempsey, Keen, Pennell, O'Reilly \& Neilands (2009) found that, for mothers, having a child with intellectual disability was more of an emotional crisis than it was for fathers. Fathers were more concerned about the future achievements of the intellectually disabled child, but mothers evidenced more concern about the child's social relationships.

Some studies have demonstrated that there are differences between fathers and mothers in their reactions toward having a child with intellectual disability disorder. As compared to mothers, the fathers in Blacher, Neece, \& Paczkowski's (2005) study: (1) had more difficulty coping; (2) were more concerned about the stigma of having a child with IDD; and (3) reacted differently depending on the sex of the child. Fathers evidenced either extreme involvement with or complete withdrawal from their sons whereas they evidenced a limited, routine involvement with their daughters.

Head \& Abbeduto (2007) reported that fathers of chronically ill and developmentally disabled children demonstrated a diminished sense of competence as parents and more readily admitted to the "psychic pain" they were experiencing than did mothers. Literature reviews also have indicated differences between the attitudes of parents and have suggested the consequences of these differences. According to Plant \& Sanders (2007), there may be differences in mothers' and fathers' reactions to an intellectually disabled child, in their emotional reactions, concerns, and patterns of acceptance. Lamb (1983) concluded that the fathers are likely to react negatively to their intellectual disabled children and that their rejecting and withdrawing behaviors will result in mothers bearing more of the "burden," which, in turn, may adversely affect their marriages. 
The severity of the child's handicap influences parental attitudes. A differential effect for different handicaps appears to exist; and in addition to severity, acceptance appears to depend upon interaction of a number of variables (e.g., social acceptability socioeconomic sex and age of the child. According to Mori (1983) \& Zheng et al. (2014), parents differentially respond to different types of handicaps. For example, parents of learning disabled children may have a difficult time accepting the diagnosis and redefining the expectations they have for their child because the child displays many appropriate behaviors; whereas parents of intellectually disabled children may exhibit overprotection, and those of the physically impaired will not be able to accept the fact they are having a deformed child.

Different types of handicaps are regarded more or less positively by societal members; as Kandel and Merrick (2005) asserted the attitudes of parents of handicapped children are influenced by the attitudes of societal members. Indeed it also must be recognized that prior to the experience of having a handicapped child, parents very likely had internalized societal beliefs about different handicapping conditions; now they may be faced with overcoming their belief system.

The socioeconomic status of parents has also been shown to affect parent attitudes. Although there is some evidence that low socioeconomic parents may be more rejecting (Groce, Kett, Lang \& Trani, 2011), most researchers have concluded that high socioeconomic status parents evidence greater difficulty in accepting their handicapped child (Brown, MacAdam-Crisp, Wang, \& Iaocci, 2006; Kauser, Jevne, \& Sobsey, 2003). On the other hand, lower socioeconomic status families may suffer more adverse effects because they do not have the financial resources to gain assistance in caring for the child (Gallagher, Beckman, \& Cross, 1983).

The sex of the handicapped child may also affect parental attitudes. Shamim (2002) reported that in lower class families, having a mentally retarded boy had a more acute effect on marriages than did having a retarded girl; but the sex of the child was not related to marital integration in middle class families. Rangaswami (1995) suggested that having a handicapped firstborn son is more distressing to parents than having a firstborn handicapped daughter, or later-born handicapped son. Thenggal (2013) studied mothers of retarded children involved in an early intervention program; results showed that the mothers had more difficulty in their interactions with young males with Down's syndrome than with females. These studies suggest that having a handicapped male child may be more catastrophic for parents; but since the research is limited, the question is still left open. Clearly it seems that future research must be directed toward a better understanding of the differential reactions of mothers and fathers toward various handicapping conditions. 
Most studies have focused on parental reactions to a retarded child, and it is not clear how parents may differ in their reactions to children with other developmental and intellectual disabled children.

\section{Methodology}

\section{Selection of the Participants}

It is a comparative study of identifying parents' behavioral practices towards child with intellectual disability disorder with that of family of normal children. The sampling in this study is being done on the basis of quota sampling. Thus the project of the study is:

- Total number of the families of children with IDD $=150$

- Total number of the families of normal children $=150$

For the present study the following special education centres (Table 2)have been selected through purposive sampling method for collection of samples of families of children with IDD from the metropolitan city of Karachi.

Table: 2

Selected special schools for the sample

\begin{tabular}{|l|c|}
\hline \multicolumn{1}{|c|}{ Name of Institutions } & No. of samples \\
\hline DEWA Special School Centre for Mentally Challenged Children & 70 \\
\hline PN Karsaz Special Education Centre & 60 \\
\hline Quaideen Special Education Centre & 20 \\
\hline
\end{tabular}

Only those children who were already admitted in the above mentioned institutions were taken as samples of one group. Those children who were not admitted in any special school and whose parents did not visualize any abnormality in behavior of their children were taken as the sample-group of normal children. The total number of the samples in case of children with IDD's group is 150. The total number of the samples in case of normal children's group is also 150 . Hence the parental behavioral practices of the 150 families of normal children have been used as comparison with the parental behavioral practices of the 150 families of having a child with IDD.

\section{Survey Instrument}

The principal instrument for investigation was a structured schedule filled by the investigator during the period of July 2018 to October 2018. The survey instrument includes the following details:

i. Home address

ii. Parents' name and age 
iii. Education and occupation of the parents

iv. Total income of the family

v. Type of family

vi. Mental health history of the family

vii. Age, sex and birth order of the child

viii. Nature of the child - aggressive, violent, cooperative, jealous, etc.

ix. Nature of treatment with the disordered behavior of the child

x. Attend any training program related to parent education

\section{Tabulation and Analysis of Data}

Collected data were scrutinized and edited. Tabulation work was then started. For analyzing and representing the data, it was decided to rely upon the frequency tables. Tabulation was done in such a way so that the data revealed internal logic and order.

\section{Findings}

Parents of children with IDD feel themselves isolated from the society for having such off springs that are hardly given social recognition. Father of the IDD child has lesser to do than the mother. The mother actually is often exposed to the notion of being the protector and savior of the child and she sometimes feels like blaming herself and this often has given out the expression of over-protection from mothers' side. The father on the other hand, though, generally not in favor of beating the child, often discards the child by snubbing, as he feels, he has many other problems to tackle with.

In Pakistan which is mainly composed of patriarchal type of families the man mainly has the responsibility of feeding and rearing up the children and has not so much time to be worried about the child as the mother. Obviously he has a limited behavior for the child and they can be found to be given expression in matters of scolding, beating, showing tolerance, overprotection, being frustrated, granting excessive freedom, or being totally apathetic to such children. Mothers' behavior is generally given expressions in being over protective for the child or being balanced in it. There is hardly any mother who is apathetic towards her child.

In this study, the behavior of parents has been discussed separately for both the subject groups of children with IDD and for the group of normal children.

\section{Composition of the Family Background}

Following were the characteristics of the family background of the children with IDD and normal children: 
Table: 3

Characteristics of the sampled families

\begin{tabular}{|l|c|c|c|c|c|}
\hline Variables & \multicolumn{5}{|c|}{ Sub-Group Data } \\
\hline Age of fathers of children with & $20-30$ & $30-40$ & $40-50$ & $50-60$ & $>60$ \\
IDD(in years) & $4[3 \%]$ & $74[49 \%]$ & $46[31 \%]$ & $22[14 \%]$ & $4[3 \%]$ \\
\hline Age of mothers of children with & $20-30$ & $30-40$ & $40-50$ & $50-60$ & $>60$ \\
IDD(in years) & $28[18 \%]$ & $76[51 \%]$ & $42[28 \%]$ & $4[3 \%]$ & $0[0 \%]$ \\
\hline Age of fathers of normal & $20-30$ & $30-40$ & $40-50$ & $50-60$ & $>60$ \\
children(in years) & $4[3 \%]$ & $68[45 \%]$ & $52[35 \%]$ & $20[13 \%]$ & $6[4 \%]$ \\
\hline Age of mothers of normal & $20-30$ & $30-40$ & $40-50$ & $50-60$ & $>60$ \\
children(in years) & $28[18 \%]$ & $88[59 \%]$ & $28[19 \%]$ & $4[3 \%]$ & $1[1 \%]$ \\
\hline Socio-economic status of the & $26-29$ & $16-25$ & $11-15$ & $5-10$ & $<4$ \\
families of children with IDD & $4[3 \%]$ & $28[19 \%]$ & $52[35 \%]$ & $66[43 \%]$ & $0[0 \%]$ \\
\hline Socio-economic status of the & $26-29$ & $16-25$ & $11-15$ & $5-10$ & $<4$ \\
families of normal children & $12[8 \%]$ & $38[25 \%]$ & $60[41 \%]$ & $38[25 \%]$ & $2[1 \%]$ \\
\hline
\end{tabular}

Table 3 indicates that majority of the fathers in both groups fall in the age group of $30-$ 40 years (49\% of the children with IDD and $45 \%$ fathers of normal children). The maximum number of the mothers of both groups of children comes from the same age group (51\% of the children with IDD and 59\% mothers of normal children).

To identify the social status of the respondents under study, Kuppuswamy's (1959) standardized socio-economic status measurement scale is employed having in view the head of their household as the bearer of the component of the socio-economic status. The class position is determined through the status score values which vary as follows: $26-$ 29 elite class; 21 - 25 upper-middle class; 16 - 20 middle-middle class; 11 - 15 lowermiddle class; 5 - 10 lower-lower class and below 4 the destitute. The score value was determined through sum total scores of three major criteria including income, occupation and educational level of fathers.

Table 1 indicates that in families of children with IDD, forty three percent ( 66 or $43 \%$ ) of the respondents are under the score of $5-10$, which is assumed as lower-lower status score under the present status. Only 3\% $(\mathrm{N}=4)$ of the families in this group are found from the category of $26-29$ score which constitute the elite class status. Hence, it can be said from the study of the above figures that the respondents from families of children with IDD constituting the maximum number are from the lower socio-economic strata of the society comparing to families of normal children who were scored $11-15$ in majority which is assumed as lower-middle class status. 


\section{Behavior of Father towards the Child}

Behavior of fathers towards their normal and children with IDD has been examined by asking them few questions. The results obtained are tabulated below.

Table: 4

Behavior of fathers towards the normal and children with IDD

$(\mathrm{N}=150$ in each group)

\begin{tabular}{|l|c|c|c|c|c|c|}
\hline \multirow{2}{*}{ Reaction of Behavior } & \multicolumn{3}{|c|}{$\begin{array}{c}\text { Behavior towards the } \\
\text { Children with IDD }\end{array}$} & \multicolumn{3}{c|}{$\begin{array}{c}\text { Behavior towards Normal } \\
\text { Children }\end{array}$} \\
\cline { 2 - 7 } & Yes & No & $\begin{array}{c}\text { Some- } \\
\text { times }\end{array}$ & Yes & No & $\begin{array}{c}\text { Some- } \\
\text { times }\end{array}$ \\
\hline Scolding & 112 & 18 & 20 & 30 & 120 & 00 \\
& {$[75 \%]$} & {$[12 \%]$} & {$[13 \%]$} & {$[20 \%]$} & {$[80 \%]$} & {$[0 \%]$} \\
\hline Beating & 22 & 88 & 40 & 42 & 96 & 12 \\
& {$[15 \%]$} & {$[59 \%]$} & {$[26 \%]$} & {$[28 \%]$} & {$[64 \%]$} & {$[8 \%]$} \\
\hline Tolerating & 54 & 94 & 02 & 18 & 132 & 00 \\
& {$[36 \%]$} & {$[63 \%]$} & {$[1 \%]$} & {$[12 \%]$} & {$[88 \%]$} & {$[0 \%]$} \\
\hline Over-Protection & 28 & 122 & 00 & 16 & 134 & 00 \\
& {$[19 \%]$} & {$[81 \%]$} & {$[0 \%]$} & {$[11 \%]$} & {$[89 \%]$} & {$[0 \%]$} \\
\hline Frustrated & 34 & 116 & 00 & 06 & 144 & 00 \\
& {$[23 \%]$} & {$[77 \%]$} & {$[0 \%]$} & {$[4 \%]$} & {$[96 \%]$} & {$[0 \%]$} \\
\hline Fulfilling all desires & 20 & 100 & 30 & 32 & 118 & 00 \\
& {$[13 \%]$} & {$[67 \%]$} & {$[20 \%]$} & {$[21 \%]$} & {$[79 \%]$} & {$[0 \%]$} \\
\hline Granting excessive freedom & 16 & 126 & 08 & 18 & 132 & 00 \\
& {$[11 \%]$} & {$[84 \%]$} & {$[5 \%]$} & {$[12 \%]$} & {$[88 \%]$} & {$[0 \%]$} \\
\hline Apathetic & 24 & 114 & 12 & 00 & 150 & 00 \\
& {$[16 \%]$} & {$[76 \%]$} & {$[8 \%]$} & {$[0 \%]$} & {$[100 \%]$} & {$[0 \%]$} \\
\hline
\end{tabular}

In case of 150 families that have been examined 112 (75\%) fathers of children with IDD are in favor of scolding them often and $20(13 \%)$ in favor of scolding sometimes, but this attitude is not so in matter of beating or otherwise punishing the child. Of course, child with IDD has been found to be tolerated by their fathers and some have taken an apathetic attitude towards them whereas in case of normal children there has been no apathetic attitude and there are lesser scolding them than the child with IDD.

\section{Behavior of Mother towards the Child}

Behavior of the mother towards her child has been found generally of over protection for the child with IDD than in case of normal child. Of course, mothers are not at all apathetic to their children both the cases of normal as well as children with IDD. Behavior of mothers analyzed for both the groups of children can be tabled as shown below. 
Table: 5

Behavior of mothers towards their children

\begin{tabular}{|l|c|c|c|c|c|}
\hline \multicolumn{1}{|c|}{ Families } & $\begin{array}{c}\text { Over- } \\
\text { Protection }\end{array}$ & $\begin{array}{c}\text { Excessive } \\
\text { Freedom }\end{array}$ & Apathetic & Balanced & Total \\
\hline $\begin{array}{l}\text { Families have a Child } \\
\text { with IDD }\end{array}$ & $\begin{array}{c}112 \\
{[75 \%]}\end{array}$ & $\begin{array}{c}08 \\
{[5 \%]}\end{array}$ & $\begin{array}{c}00 \\
{[0 \%]}\end{array}$ & $\begin{array}{c}30 \\
{[20 \%]}\end{array}$ & $\begin{array}{c}150 \\
{[100 \%]}\end{array}$ \\
\hline $\begin{array}{l}\text { Families have normal } \\
\text { Children }\end{array}$ & 20 & 10 & 00 & 120 & 150 \\
{$[13 \%]$} & {$[7 \%]$} & {$[0 \%]$} & {$[80 \%]$} & {$[100 \%]$} \\
\hline
\end{tabular}

Table 5reveals that there are many mothers of children with IDD, i.e., (112 out of 150 families) who by over-protection damaging their child's personality and dependency has been appeared as a consequent behavior among them. There are many children with IDD in this study who have failed twice or thrice in a class due to over-protection of their mothers (as admitted by the mothers of such children).

\section{Discussion}

The comparative data that have been collected by the investigators showing child-parent relationship can be concluded as follows:

1) The child with IDD in the family setting may be rejected in numerous ways. An unstable or indifferent mother, a mother who is over burdened with the care of many children or a mother who is antagonistic towards her baby or her role as mother may provide minimal physical care unembellished by personal warmth or by an environment in which there is variety, stimulation and responsiveness. Other expressions of rejection tend to be more active and to be reflected in hostility in the emotional atmosphere and in mishandling rather than in ignoring the child. The evidence indicates, however, that without adequate stimulation both the emotional and intellectual development of the child may be retarded.

2) As the study reveals, most of the parents of the children with IDD have the attitude of punishing the child. But it is much harmful because it can further retard the mental growth of the child. Generally, hostile and discouraging environments affect seriously in the later life of the intellectual disability disordered child. The literature evidences the negative attitudes parents may have toward child with IDD (Kumar \& Joshi, 2015) and children with Down syndrome (Takataya, Yamazaki \& Mizuno, 2016). Also, Dhar (2009) and Hagborg (1989) indicated that negative parental attitudes were associated with demanding, neglecting, and punishing behaviors toward the child with disability. Another study (Lalvani \& Polvere, 2013) showed that the negative attitudes parents expressed toward their intellectually disabled child on a rating scale related to the amount of rejecting behaviors professionals observed during home visits.

3) The findings suggest that, for mothers, having a child with IDD was more of an emotional crisis than it was for fathers. Fathers were more concerned about the future achievements of the child, but mothers evidenced more concern about the 
child's social relationships. Howe (2006) reported that fathers of mentally challenged children demonstrated a diminished sense of competence as parents and more readily admitted to the psychic pain they were experiencing than did mothers.

The relationship of the intellectually disability disordered child with his parents is more important than the relationship of the intellectually normal child with his parents (Wilkin, 2016). His personality including his emotional stability or instability is to a considerable extent a reflection of the personalities and stability of his parents (Newson, 2017).

The parents of a child with IDD are in a different situation. Because of the attitude of the society they may feel ashamed of their offspring and the feeling of shame may result in overt or covert rejection (Chowdhury, 2018). Many families drastically alter their way of life because of the presence of a child with intellectually challenged in the family circle and withdraw from community activities almost completely (McConachie, 2016).

\section{Recommendations}

Professionals can help parents of children with intellectual disability disorder (IDD) to achieve a more positive attitude toward, and consequently a better relationship with, their child. And the attitudes and interactions a handicapped child experiences in the home environment may significantly impact upon his/her future growth and development.

There are several approaches for helping parents of children with handicapped achieve acceptance of their child. Among the major strategies are: (1) individual counseling; (2) group counseling; (3) family therapy; and (4) biblio therapy. Involving parents in the education of these children, primarily by teaching them how to use behavioral management techniques to modify their child's behavior has been increasingly advocated and may also contribute to an attitudinal change.

\section{References}

Blacher, J., Neece, C. L. \& Paczkowski, E. (2005).Families and Intellectual Disability. Current Opinion in Psychiatry, vol.18:5, pp.507-513.

Brown, R. I., MacAdam-Crisp, J., Wang, M. \& Iaocci, G. (2006). Family Quality of Life When There is a Child with a Developmental Disability. Journal of Policy and Practice in Intellectual Disabilities, vol.3:4, pp.238-245(8).

Bryant, J. E. (1971). Parent-child relationships: Their effect on rehabilitation. Journal of Learning Disabilities, vol.4, pp.325-329.

Chowdhury, P. (2018). Attitude of Parents towards a Handicapped Family Member: A Review. Asian Journal of Research in Social Sciences and Humanities, vol.8:2, pp.224-238. 
Dabrowska, A. \& Pisula, E. (2010). Parenting Stress and Coping Skills in Mothers and Fathers of Pre-school Children with Autism and Down Syndrome. In Journal of Intellectual Disability Research, vol.54:3, pp.266-280.

Dempsey, T., Keen, D., Pennell, D., O’Reilly, J. \& Neilands, J. (2009). Parent Stress, Parenting Competence and Family-Centered Support to Young Children with an Intellectual or Developmental Disability. Research in Developmental Disabilities, vol.30, pp.558-566.

Dhar, R. L. (2009). Living with a Developmentally Disabled Child: Attitude of Family Members in India. The Social Science Journal, vol.46:4, pp.738-755.

Ferguson, P. M. (2002). A Place in the Family: An Historical Interpretation of Research on Parental Reactions to Having a Child with a Disability. The Journal of Special Education, vol.36:3, pp.124-131.

Fleron, J. (2017). Special Children, Special Risks: The Maltreatment of Children with Disabilities. Routledge.

Gallagher, J. J. (1956). Rejecting Parents.Exceptional Children, 22, 273 - 276, 294.

Gallagher, J. J., Beckman, P. \& Cross, A. H. (1983). Families of Handicapped Children: Sources of Stress and its Amelioration. Exceptional Children, 50, 10-19.

Groce, N., Kett, M., Lang, R. \& Trani, J. (2011). Disability and Poverty: The Need for a More Nuanced Understanding of Implications for Development Policy and Practice. Third World Quarterly, 32:81493-1513.

Hagborg, W. J. (1989). A Comparative Study of Parental Stress among Mothers and Fathers of Deaf School-Age Children. Journal of Community Psychology, vol.17:3, pp.220-224.

Hasnat, M.J. \& Graves, P. (2000). Disclosure of Developmental Disability: A Study of Parent Satisfaction and the Determinants of Satisfaction. Journal of Pediatrics \& Child Health, vol.36, pp.32-35.

Hastings, R.P. (2003). Child Behavior Problems and Partner Mental Health as Correlates of Stress in Mothers and Fathers of Children with Autism. In Journal of Intellectual Disability Research, vol.47:4-5, pp.300-312.

Head, L. S. \& Abbeduto, L. (2007).Recognizing the Role of Parents in Developmental Outcomes: A Systems Approach to Evaluating the Child with Developmental Disabilities. Mental Retardation and Developmental Disabilities, 13, 293-301. 
Horne, M. D. (2012). Attitudes toward Handicapped Students: Professional, Peer, and Parent reactions. Routledge.

Howe, D. (2006). Disabled Children, Parent-Child Interaction and Attachment. Child \&Family Social Work, vol.11:2, pp.95-106.

Kandel, I. \& Merrick, J. (2005) Factors Affecting Placement of a Child with Intellectual Disability. The Scientific World Journal,vol.5, pp.370-376.

Kauser, S., Jevne, R. F. \& Sobsey, D. (2003). Hope in Families of Children with Developmental Disabilities. Journal on Developmental Disabilities, vol.10:1, pp.35-46.

Kumar, R. \& Joshi, H. L. (2015).Parenting Stress in Relation to Children's Problem Behaviors among Fathers of Children with Intellectual Disability. Indian Journal of Health \& Wellbeing, vol.6:11.

Kuppuswamy, B. A. (1959). A Scale to Measure Socio-Economic Status. The Indian Journal \& Psychology, vol.34, pp.109-119.

Lalvani, P. \& Polvere, L. (2013). Historical Perspectives on Studying Families of Children with Disabilities: A Case for Critical Research. Disability Studies Quarterly, vol.33:3.

Lamb, M. E. (1983). Fathers of Exceptional Children. In M. Seligman (Ed.), The Family with a Handicapped Child: Understanding and Treatment. New York: Grune\& Stratton.

McConachie, H. (2016). Parents and Young Mentally Handicapped Children: A Review of Research issues. Routledge.

Mori, A. A. (1983). Families of Children with Special Needs: Early Intervention Techniques for the Practitioner. Rockville, MD: Aspen Systems Corp.

Murray, J. N. \& Cornell, C. J. (1981).Parentalplegia. Psychology in the Schools, vol.18:2, pp.201-207.

Newson, E. (2017). The family and the handicapped child: a study of cerebral palsied children in their homes. Routledge. 
Plant, K. M. \& Sanders, M. R. (2007). Predictors of Care-Giver Stress in Families of Preschool-Aged Children with Developmental Disabilities. Journal of Intellectual Disability Research, vol.51:2, pp.109-124.

Psaila, E. (2016). Parenting a Child with Intellectual Disability - Factors That May Contribute in Making Parenthood a Positive Experience. University of Malta, Imsida.

Rangaswami, K. (1995). Parental attitude towards mentally retarded children. Indian Journal of Clinical Psychology, vol.22:1, pp.20-23.

Shamim, M. (2002).Impact of having Children with Mental Retardation in the Family. Ability and Success, vol.6:4, pp.34-35.

Takataya, K., Yamazaki, Y. \& Mizuno, E. (2016).Perceptions and Feelings of Fathers of Children with Down Syndrome. Archives of Psychiatric Mursing, vol.30:5, pp.544-551.

Thengal, N. (2013). Attitude of Parents and Family Members towards their Mentally Retarded Children. International Journal of Behavioral Social and Movement Sciences, vol.02:01, pp.196-210.

Thomas, D. (2015). The Social Psychology of Childhood Disability. Psychology Press.

Wilkin, D. (2016). Caring for the Mentally Handicapped Child. Routledge.

Zheng, Q. L. \&et al., (2014). The Role of Quality of Care and Attitude towards Disability in the Relationship between Severity of Disability and Quality of Life: Findings from a Cross-Sectional Survey among People with Physical Disability in China. Health and Quality Life Outcomes, 12:25.

Dr. Shaista Naz is an Assistant Professor in the Department of Special Education, University of Karachi.

Dr. Nasir Sulman is Dean, Faculty of Education, University of Karachi. 